\title{
COMPARATIVE STUDY OF THE DYNAMIC PERFORMANCE OF PROMISING DISTRIBUTED GENERATING UNITS
}

\author{
Ahmed M. Azmy, F. EL-Dosary, G. El-Saeed, M. EL-Khazendar \\ Department of Electrical Power and Machines Engineering, Faculty of Engineering, \\ Tanta University, Tanta, Egypt
}

\begin{abstract}
The deregulation and liberalization of electricity market besides the increasing interest of carbon emissions and eliminating unnecessary transmission and distribution costs encourage the utilization of Distributed Generation " $D G$ ". Therefore, $D G$ is expected to penetrate within electrical power systems in the near future in the form of small generating sources located close to load centres. This paper discusses the dynamic performance of some promising Distributed Generating (DG) units. The selected units in this study are the wind turbine, the fuel cell, the micro turbine and the hybrid fuel cell-micro turbine unit. The objective is to compare among the dynamic performances of such units to evaluate their behaviour under different operating conditions. Detailed models for the selected units including the thermal description of the fuel cell are presented. The investigation study concentrates on the operation of the DG units with an isolated load. Extensive simulation results are introduced to enable the comparison among different units.

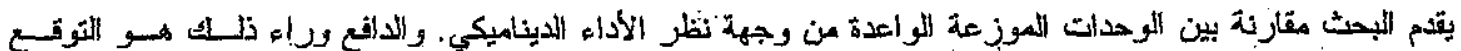

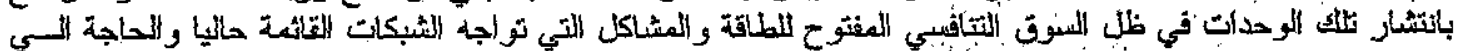

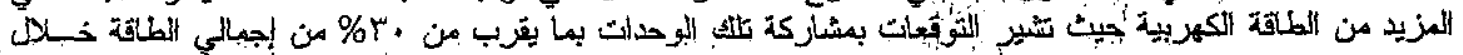

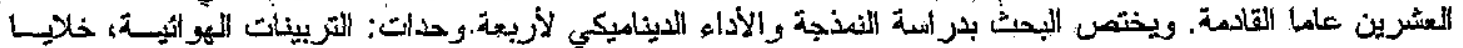

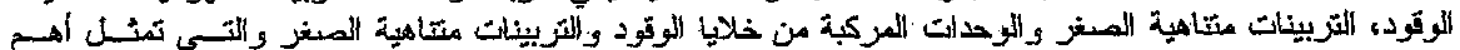

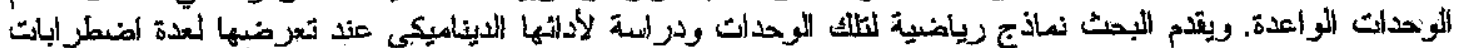

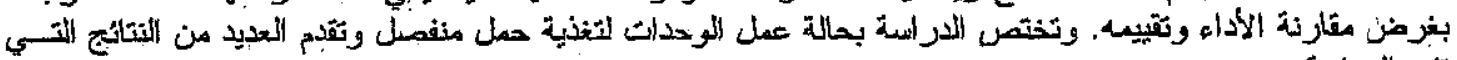
تقيد الدزاسة.
\end{abstract}

Keywords: Distributed generation, Dynamic modelling, Fuel cell, Hybrid fuel cell-micro turbine, Micro turbine, Wind turbine.

\section{INTRODUCTION}

The conventional generation of electrical power can not follow up the continuous increase of load demand. The problem is not associated simply with the installation of new power stations. Rather, the problem is extended to include the expenditures of transmission and distribution systems' with high investments [1]. Identifying the problems related to conventional sources directed a high concentration on new set of power supply requirements that can better be served through Distributed Generation (DG) [1]. Therefore, the penetration levels of such sources and their contribution in electric power systems are gradually growing as a means of supporting the existing power networks. [2].

Besides supporting the conventional power plants, DG can offer many other benefits when suitable types, sizes and locations are selected. Examples of such benefits include: reducing the greenhouse gasses, increasing the system efficiency, reducing the transmitted power, improving the voltage profile and improving the power quality and reliability [3]. However, the utilization of DG in large scales obligates solving the corresponding technical and operational chatlenges such as interface problems, control strategy and protection system design. Solving these problems is necessary to obtain a satisfactory operation and ensure a reliable and safe performance [4].

One of the most important issues related to $D G$ is the dynamic performance of individual gerierating units that can impact the power quality at the consumer terminals [5]. Despite the importance of this issue for stand-alone loads, it is also of great significtance when DG units are connected to the thain grid system. The fast response to load variations, possibility of effective voltage regulation and limited overshoots are basic 
requirements of any DG unit regarding the dynamic performance [6]. Therefore, the dynamic performance of these units has to be investigated with suitable control strategies.

Variable-Speed Wind Turbines (WT) offer environment-xriendly type of DG that are well developed and widely used in electric power systems [7]. Micro-Turbines (MTs) have compact and simple design, low maintenance requirements and can produce low-cost low-emission electricity. Other advantages include: durability, load-following capabilities, ability to operate on a variety of fuels and the possibility of Combined Hieat and Power (CHP) applications [8]. On the other hand, Fuel Cells (FCs) provide the potential for higher efficiencies, fuel flexibility in addition to the modularity, silent operation, and environmental benefits. A unique feature of FCs is their high efficiency at part of load [9].

A recently-developed DG unit is the hybrid configuration comprising a FC and MT with the MT located downward to the FC. The hybrid Fuel Cell/Micro Turbine System (FCMT) is a promising configuration that can provide many advantages. This includes the high efficiency, fuel flexibility, superior environmental performance and possibility of obtaining electric power from the two units [9]. Therefore, it is expected with the continuous developments and investigation to bring this unit into competition with other DG units.

In this paper, the dynamic modelling and performance of the abovementioned promising units are surveyed. Each of the selected DG unit is modelled with a stand-alone load and the performance is studied under different operating conditions. Detailed modelling for each unit is used to ensure accurate results, and hence reliable conclusions and recommendations are extracted. The WT is modelled when driving a synchronous generator with detailed differential equations. Regarding the FC unit, both the electrical and thermal behaviour are considered. In addition, MT is modelled with the well-known blockdiagram dynamic model with a permanent-magnet synchronous generator. Finally, the hybrid unit is represented using the models of the individual $\mathrm{FC}$ and MT units with suitable interconnection between them.

The general discussion concentrates on the dynamic performance of the units and the comparison between them. In addition, feasibility of the control system and the possible cause of disturbances associated with each unit are discussed.

\section{WIND ENERGY SXSTEM}

Figure 1 illustrates a schematic diagram of the wind energy system. The relations describing the operation of the wind turbine are as follows: The equation describing the mechanical torque converted from wind power is given by the following equation [10]:

$$
T_{m}=\frac{1}{2} \rho \cdot \tau_{g b} \cdot A_{s} \cdot C_{p} \cdot R \frac{V_{W}^{2}}{\lambda}
$$

The tip-speed ratio can be calculated using the following relation:

$$
\lambda=\frac{\text { speed of tip }}{\text { wind speed }}=\frac{R \Omega}{V_{W}}
$$

Typical power coefficient-tip speed ratio curves are used to derive the relation between tip speed ratio and power coefficient at different blade pitch angles. Such relations are given using curve fitting technique in the following form:

$$
C_{p}=C_{1}(\beta)+C_{2}(\beta) \cdot \lambda+C_{3}(\beta) \cdot \lambda^{2}
$$

Where:

$A_{s}$ : is the swept area $\left(\mathrm{m}^{2}\right)$

$C_{1}, C_{2}$ and $C_{3}$ : are functions of the blade pitch angle $(\beta)$

$\mathrm{C}_{\mathrm{p}}$ : is the coefficient of performance "power coefficient"

$R$ : is the rotor radius of the wind turbine (m)

$V_{W}$ : is the wind speed $(\mathrm{m} / \mathrm{s})$

$\eta_{\mathrm{gb}}$ : is the efficiency of the mechanical gearing

$\rho:$ is the air density $\left(\mathrm{kg} / \mathrm{m}^{3}\right)$

$\lambda:$ is the tip-speed ratio

$\Omega:$ is the angular speed $(\mathrm{rad} / \mathrm{s})$

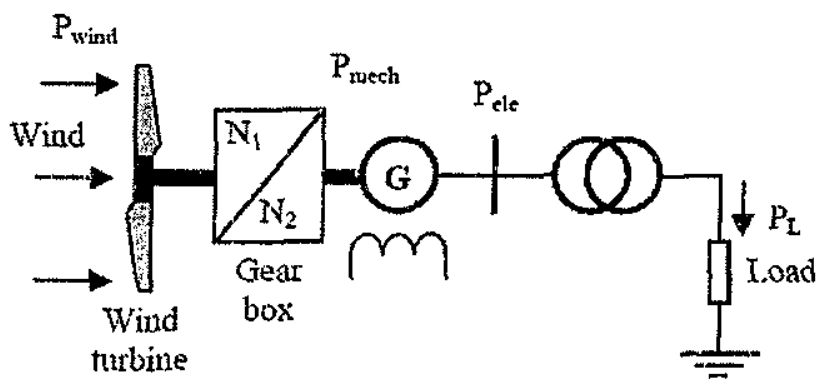

Fig 1, A schernatic diagram of the proposed system

Modified electromechanical Park's equations are used to model a salient-pole synchronous generator driven by the wind turbine in the stand-alone mode [11]. The sub-transient model of the synchronous generator comprises five differential equations describing the states of the generator, an electromechanical differential equation in addition to the differential equation of the exciter. Thus, the model 
of the wind energy system is a seven-order model. The order of the model increases to the ninth order when the PI controllers are considered. Two PI controllets are developed to manage the exciter of the generator and the blade pitch angle of the turbine.

The PI controller regulating the exciter depends on a feedback from the terminal voltage and comparing it with the desired reference voltage. On the other hand, the PI controller regulating the blade pitch angle depends on a feedback from the angular speed and comparing it with the desired reference speed. The target is to supply a high-quality power to consumers regarding the voltage and the frequency.

\subsection{Simulation Results}

The first disturbance applied to the WT system is a $20 \%$ step increase in the load impedance. Fig 2 shows the response of the WT system to this disturbance. As a result of this load reduction, the supplied current is decreased with the same ratio at steady state (i.e. $83.3 \%$ ). This is attributed to maintaining the load voltage at its desired rated value through the control action. On the other hand, the control associated with the blade pitch angle succeeded to regulate the angular speed with $10 \%$ overshoot. The angular speed returned to the steady state value within 10 second.
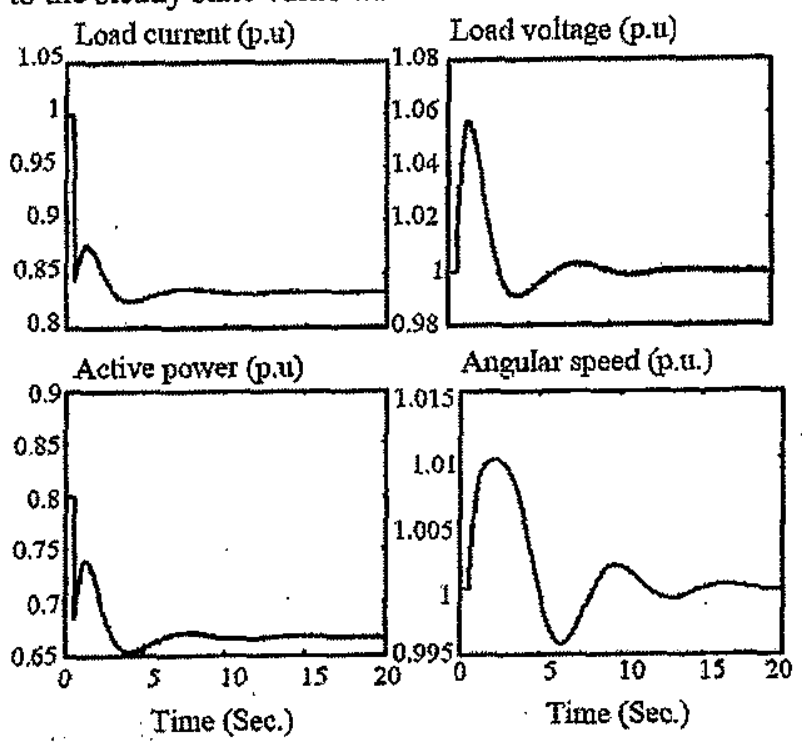

Fig 2, Response of the WT to a $20 \%$ step increase in load impedance

The second disturbance is a $20 \%$ step increase in the wind speed as shown in Fig 3 . The increase in the wind speed causes a corresponding increase in the variables of the WT system. This includes the current, voltage, power and angular speed. However, due to the control action, both the terminal voltage and the angular speed returned back to their desired values within 12 second. The overshoots associated with the current and power, however, are considerably high.

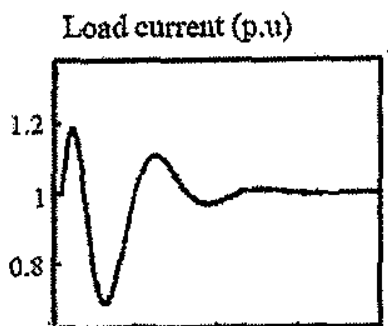

Load voltage (p.u)
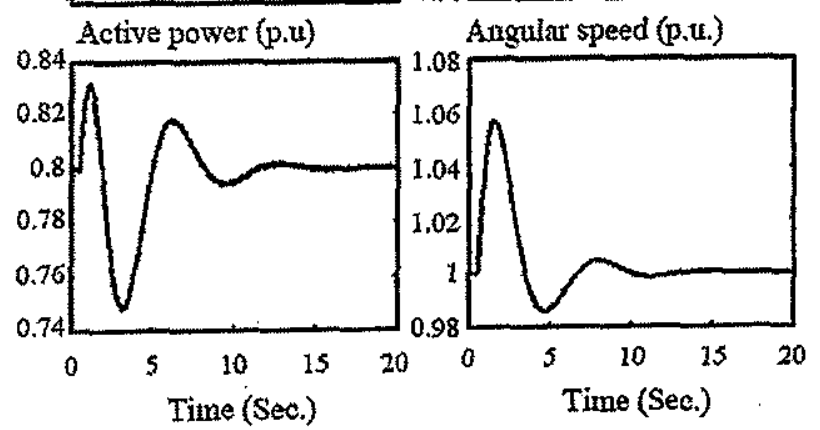

Fig 3, Response of the WT to a $20 \%$ step increase in the wind speed

\section{FUEL CELL SYSTEM}

Fig 4 illustrates the block-diagram model describing the dynamics of the FC units [5]. The modelling of the FC unit depends on the modelling of the three main parts of the system: the reformer, the stack, and the power conditioner. The production of the hydrogen inside the reformer from the input fuel requires a delay time, which is modelled as a first-order time delay elements. The time delay "Ts" is relatively high depending on the size and type of the FC itself. $\mathrm{ADC}$ $\mathrm{AC}$ pulse-width modulation (PWM) inverter is used to convert the $\mathrm{DC}$ power from the stack to $\mathrm{AC}$ power. During the conversion of the power, both the frequency and the voltage of the fuel cell are regulated.

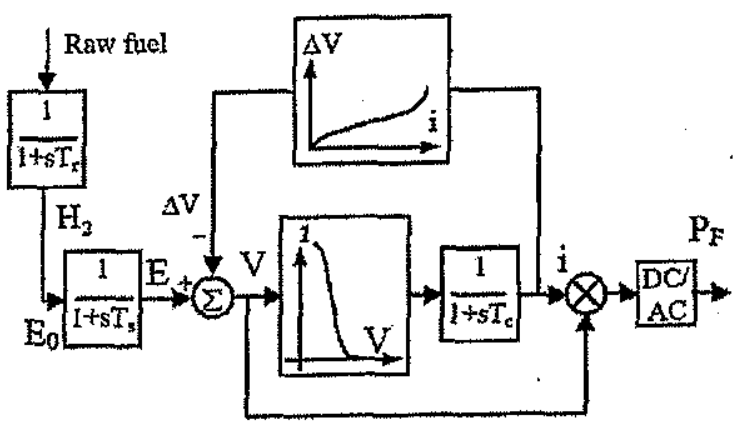

Fig 4, Modelling of the fuel cell 
Regarding the stack, three actions are modelled. Firstly, a first-crder time delay element is introduced with a time constant of (Tc), which is lower than that of the reformer [5]. The simulation of the steady-state characteristic of the FC is accomplished by introducing a non-linear resistance to represent all kinds of voltage drops in the stack. The resistance, which represent the voltage-current characteristics, can be obtained from real measurements or using the Nernest and ButlerVolmer equations [12]. A non-linear function is developed using the curve fitting technique to derive the resistance as a function of the supplied current. Typical V-I characteristics are used to develop the lossresistances as functions of the supplied currents for the FC. Finally, an inductor is introduced to take into account the time constant associated with the current.

The symbols used in Fig 4 are as follows:

$E_{0}$ is the open circuit reversible cell potential (representing the input fuel rate), "p.u."

$\mathrm{T}_{\mathrm{r}}$ is the reformer time delay, "s"

$T_{s}$ is the stack time delay, "s"

$T_{c}$ is the time constant associated with the current, "s"

$E$ is the output of the reformer (input to the stack), "p.u."

$\Delta V$ is the total voltage drop in the stack, "p.u."

$P_{F C}$ is the output power from the fuel cell, "p.u."

The operation of FCs necessitates maintaining the stack temperature constant under all operating conditions. The recovers thermal power from the stack is high enough to be used in cogeneration applications. The use of the thermal power increases the overall efficiency especially since the thermal power exceeds, in many cases, the electrical power. The heat recovery system comprises a heat exchanger and a water storage tank. A certain fluid can be used to absorb the generated heat in the stack and then it is used as a first fluid in the heat exchanger [13]. The stack temperature is controlled by regulating the mass flow rate of this fluid through a PI controller.

A second fluid (water in most cases) is used in the heat exchanger to absorb the thermal power from the first fluid and at the same time to cover the thermal load demand [13]. The mass flow rate of the second fluid is regulated through a PI controller to keep its temperature always constant to be suitable for the utilization of consumers.

The full model of the $\mathrm{FC}$ has twelve differential equations: three equations describe the reformer and stack, five equations for the heat recovery systern and four equations for the PI controllers. The systern is subjected to many disturbances to examine its dynamic performance. Only two disturbances will be introduced in the following. The first disturbance is a $20 \%$ step increase in the load impedance similar to that simulated with the WT unit. The response of the FC system to this disturbance is shown in Fig 5. From the figure, it is clear that the response of the FC is very fast since it is restricted by the time constants of the stack and the current. These time constants are relatively small and hence, fast response is obtained. However, the temperature needs longer time to reach its steady-state value due to the longer thermal time constant. Regarding the overshoots, large deviations in the voltage and power are remarkable, but the current and temperatures did not experience such large overshoots. Generally, regulated performance is obtained, where both the voltage and temperature are returned back to their initial values.
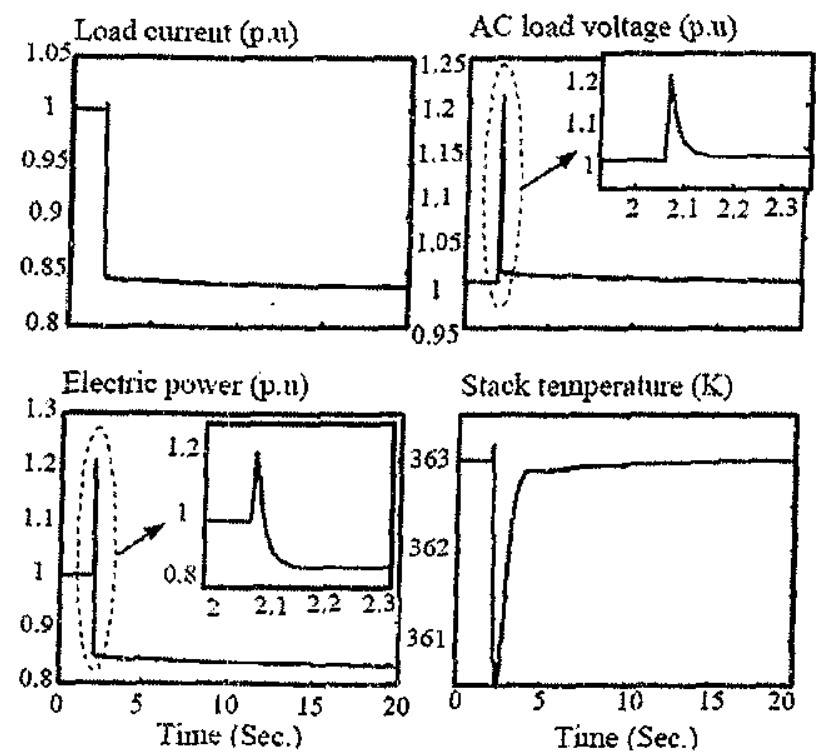

Fig 5, Response of the FC to a $20 \%$ step increase in load impedance

The second disturbance is a $20 \%$ step increase in the input fuel rate. Fig 6 shows the response of the FC unit to this disturbance. In this case, the response is slower than the previous case. The reason is attributed to the action of the reformer delay. Since the input fuel rate is changed, the hydrogen rich gas needs a delay time depending on the time constant of the reformer. As abovementioned, the time constant of the reformier is much longer than that of the stack. Therefore, the response is significantly slower than that obtained when the load impedance is changed, where there was no contribution of the reformer delay. 
The load voltage is increased as a result of increasing the input fuel rate with about $12.5 \%$ overshoot but the controller succeeded to force it to return to its initial value. The current has a similar behaviour since the load impedance is kept constant and hence, the load power is affected strongly by the disturbance.
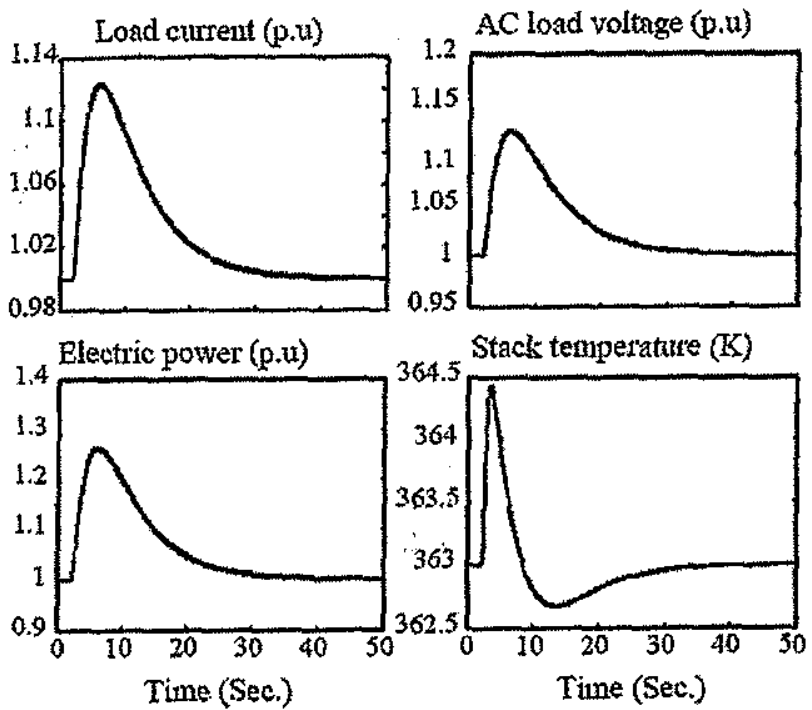

Fig 6, Response of the FC to $20 \%$ step increase in the input fuel rate

\section{MICRO TURBINE SYSTEM}

MTs represent a new generation of conventional gas turbines that are characterized by small and compact construction and high-speed operation. The MT unit consists of three main parts, which are the compressor, the combustor, and the turbine. Similar to conventional gas turbines, the compressor is used to pressurize the air, which is then forced to enter the combustor [8]. At the same time, a certain amount of fuel is injected and mixed with the compressed air in the combustor and the mixture is ignited. Then, the hot combustion gases flow and expand through the turbine and thus, mechanical energy is extracted [8]. Unlike conventional gas turbines, a Permanent Magnet Synchronous Generator (PMSG) is used to convert the mechanical energy of the turbine to electrical energy. At the same time, a part of the turbine power is utilized for driving the air compressor.

The speed of the MT is very high to be interfaced directly to the load. Therefore, a methodology for reducing the frequency is required. In this research, a cycloconverter is used to reduce the frequency and at the same time to regulate the terminal voltage. This is accomplished through two PI controllers. For simplicity, the PMSG is represented in this study by a simple first order model. Fig 7 shows the block diagram of the micro-turbine dynamic model [14].

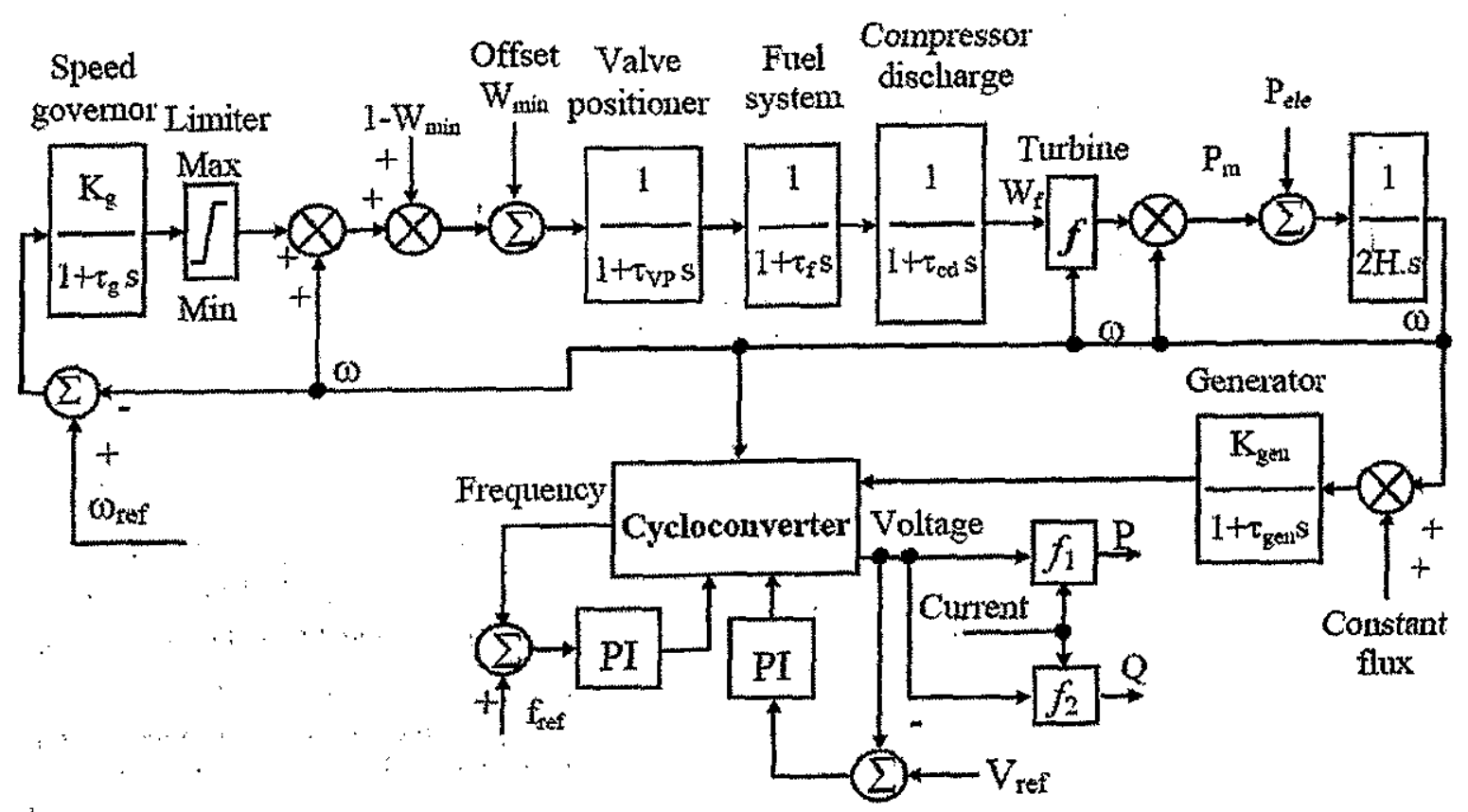

Fig 7, Model of the micro-turbine generating unit 
The turbine is simulated using the well-known function " $f$ " as follows

$$
f=1.3\left(\mathrm{~W}_{\mathrm{f}}-\mathrm{W}_{\text {min }}\right)+0.5(1-\omega)
$$

The main symbols in the figure are as follows:

$\mathrm{H}$ : inertia constant

$\mathrm{K}_{\mathrm{g}}, \mathrm{K}_{\mathrm{gen}}$ : gains of speed governor and generator respectively

$V_{\text {ref }}, f_{\text {ref, }}, \omega_{\text {ref }}:$ reference voltage, frequency, and angular speed respectively.

$P_{\mathrm{rc}}, \mathrm{P}_{\mathrm{ele}}, \mathrm{P}_{\mathrm{mi}}$ : power from exhausi air, input-electrical, and mechanical power, respectively

$\tau_{g}, \tau_{r_{p}}, \tau_{\text {gen }}$ : lag-time constants of speed governor, valve positioner, and generator respectively

$\mathrm{W}_{\min }$ : is an offset representing the fuel demand at noload

Since: the dynamic operation of the MT is similar to that of the gas turbine, it is enough to examine the performance under one disturbance. The sinulated disturbance is a $20 \%$ step increase in the load impedance. The response of the MT is shown in Fig 8. As shown in the figure, the load variation causes a corresponding variation in the load current and the load active power. On the other hand, the terminal voltage is maintained constant with negligible overshoot. The voltage deviation did not exceed $0.3 \%$, which reflects the success of the controller to regulate the terminal voltage.
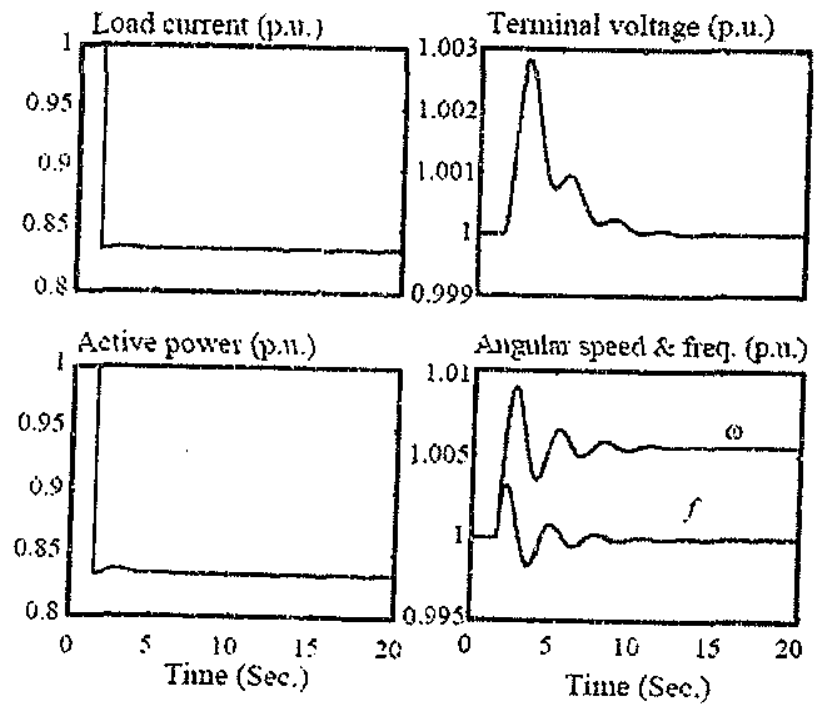

Fig 8, Response of the MT to a $20 \%$ step increase in load imperance

Regardless of the variations and steady state deviation of the angular speed, the frecuency is maintained within acceptable levels. The frequency maximum deviation is about $0.3 \%$, while that of the angular speed is about $0.9 \%$. It is not necessary in this case to regulate the angular speed itself, but the focus is to regulate the frequency.

\section{HYBRID FUEL CELL-MICRO TURBINE UNIT}

Many attempts are directed to develop a hybrid unit comprising a high-temperature $\mathrm{FC}$, an air compressor, a low capacity gas turbine, and a PMSG. In the Fuel Cell/Micro-Turbine unit "FCMT", it is possible to extract electric power from the stack and the PMSG at the same time. The downstream turbine operates in this case without combustor given that it is driven by the exhaust air from the fuel-cell [15][16]. It is required to use a start up combustor to drive the turbine and it may be used in some cases in the running mode to increase the generated power. Fig 9 illustrates the FCMT hybrid configuration. As shown in the figure, there is no direct influence of the MT on the operation of the FC. On the other hand, the operation of the turbine depends on the thermal power produced by the FC. This thermal power itself is assumed to be in proportional to the electrical power. Thus, the input thermal power to the turbine is proportional to the generated electric power in the FC.
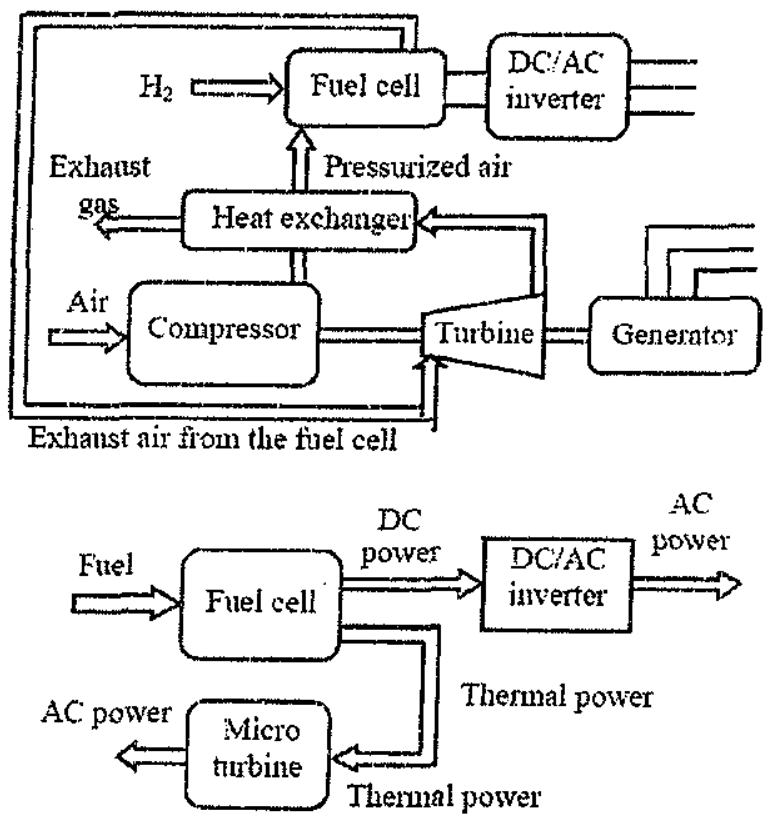

Fig 9, the FCMT hybrid configuration

For this configuration, the terminal voltage and frequency of the $F C$ are controlled by regulating the firing angles of the DC/AC converter. In addition, the terminal voltage and frequency of the turbine are controlled through the cycloconverter. The electric power of the FC can be regulated, if required, by adjusting the input fuel rate, which in turns affects the thermal power to the turbine. In this case, it is required 
to regulate this thermal power to control the generated electric power in the turbine. For this purpose, the generated power in the turbine is compared with the reference value and the error is used as an input to a PI controller to regulate the thermal power as shown in Fig 10.

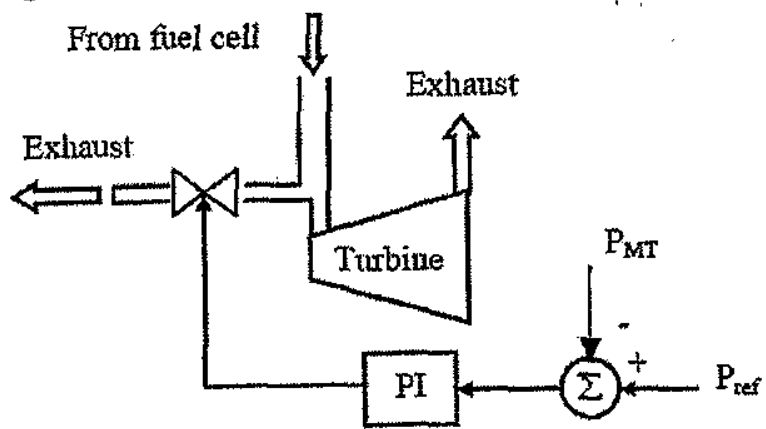

Fig 10, Regulating the generated electric power in the turbine.

The hybrid system is subjected to a $20 \%$ step increase in both load impedances connected to the FC and the MT. The response to this disturbance is shown in Fig 11. It is clear that the FC experienced higher overshoots in both voltage and power. However, the response of the FC is much faster than that of the Mt. The individual controllers succeeded to regulate the terminal voltage as well as the frequency of the MT and the stack temperature of the FC.

The increase of the load impedance causes a reduction in the generated power. As a result, a corresponding decrease in the load current takes place. Regardless of the steady state deviation of the angular speed, the frequency is maintained fixed at 1.0 p.u.

The second disturbance is a $20 \%$ step increase in the input fuel rate to the FC. The load impedances of both the FC and MT are beld constant. The target is to examine the impact of this action on the MT since the variation of the $F C$ power impacts the input thermal power to the turbine. To examine this action, no control action is introduced to regulate the thermal power from the FC. As shown in Fig 12, the disturbance causes a sustained variation in the angular speed and load current and power.

However, the terminal voltage, load frequency and stack temperature return back to rated values by controller action. Similar to the operation of the FC alone, the slow performance is caused due to the influence of the reformer delay. The variation of the MT power can be reduced or eliminated if the control action to regulate the thermal power from the $\mathrm{FC}$ is activated.

\section{GENERAL DISCUSSION AND CONCLUSIONS}

In addition to the dynamic performance, some general comparisons are given to differentiate between the different DG units. The main target is to evaluate the units as a whole regarding four main topics. The first is the existence of the combustion and mechanics, which causes any problems and increases the maintenance requirements. The second is the efficiency, which represent a quality factor. In addition; the disturbance variables are identified to highlight the source of disturbance with each unit. Finally, the control variables are clarified to demonstrate the possibility of regulating the unit performance.
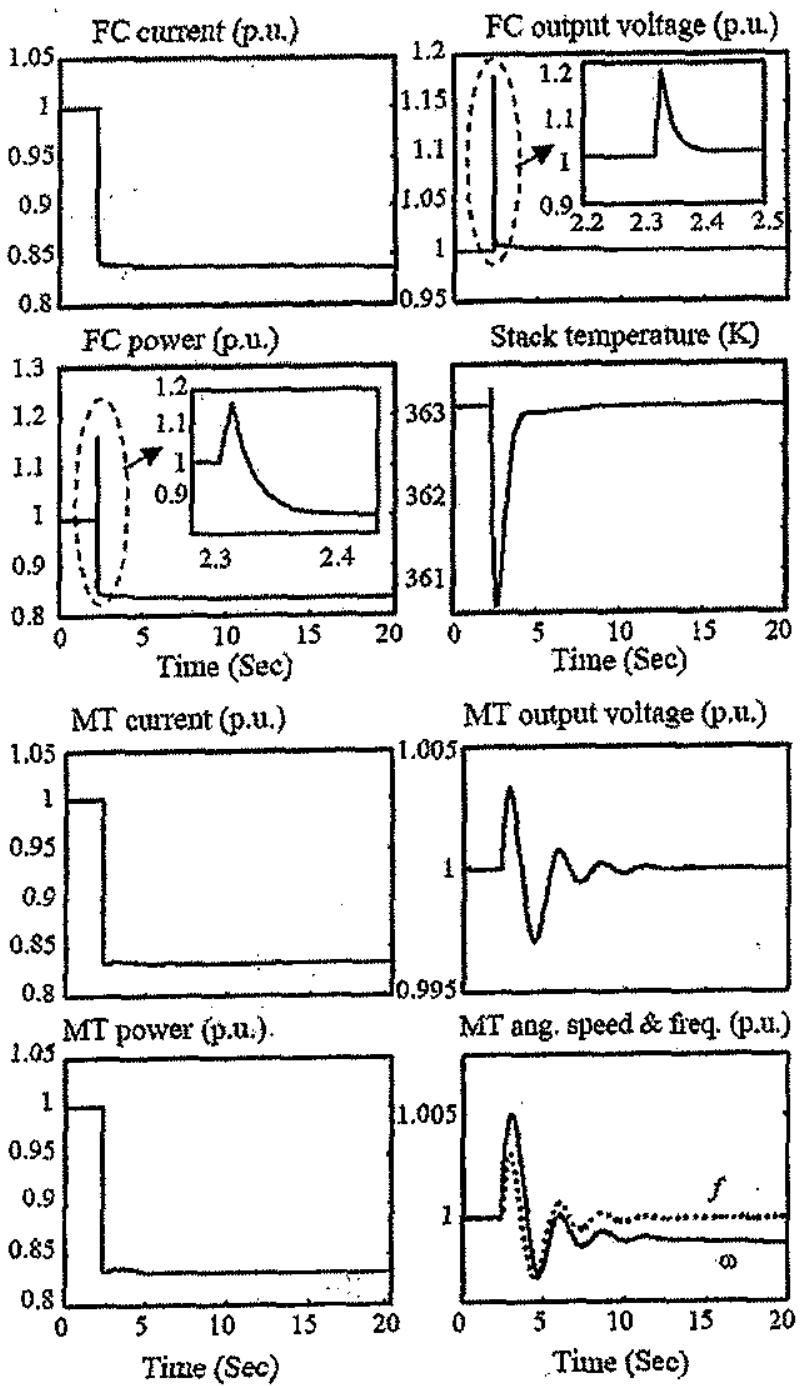

MT output voltage (p.ri.)

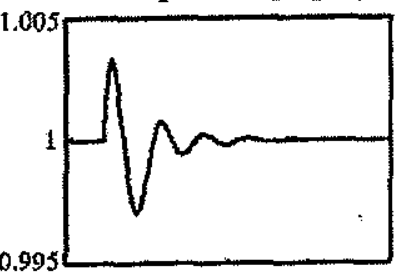

MT ang. speed \& fieq. (p.u.)

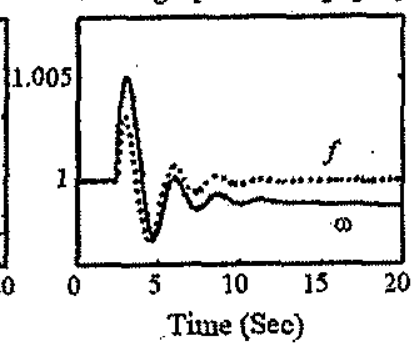

Fig 11, Response of the hybrid system to a $20 \%$ step increase in both load impedances of the FC and the MT. ., 

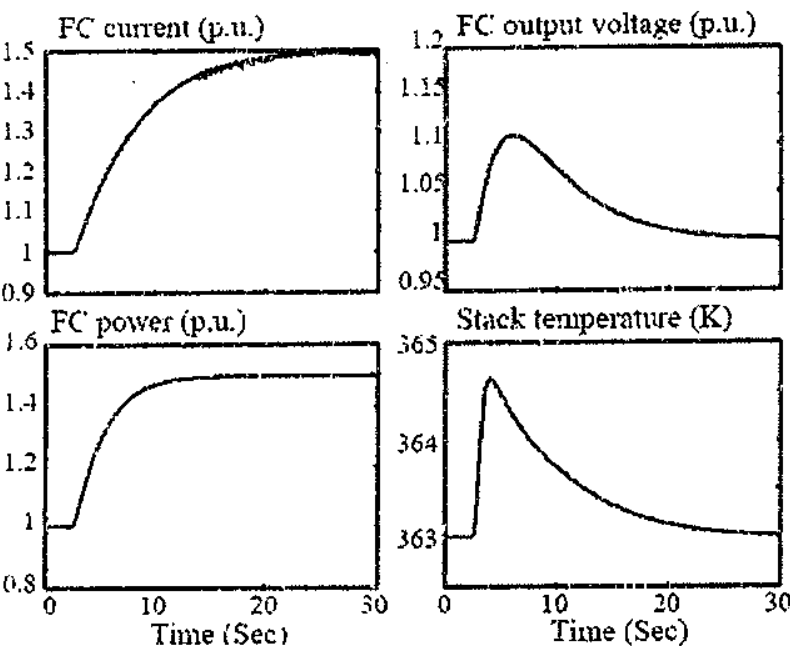

Stack temperature $(\mathrm{K})$
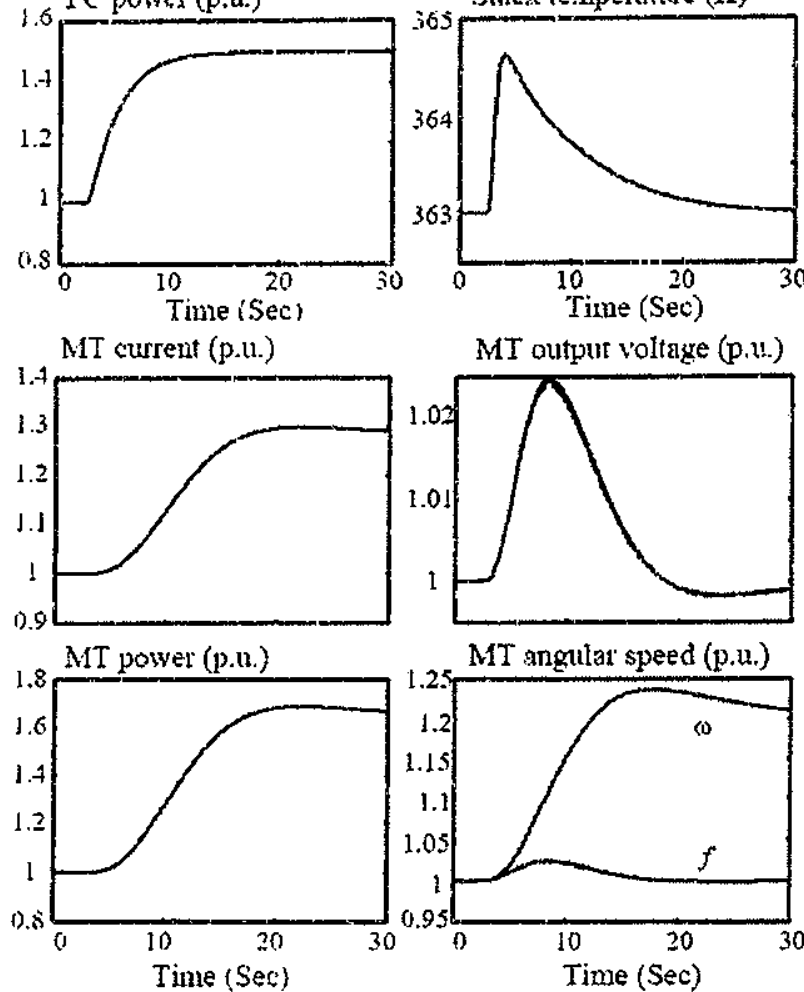

Fig 12, Response of the hybrid system to a $20 \%$ step increase in the input fuel rate of the $\mathrm{FC}$

\subsection{Regarding the combustion and mechanics}

\begin{tabular}{lcc}
\hline \multicolumn{1}{c}{ Unit } & \multicolumn{1}{c}{ Combustion } & Mechanics \\
\hline Fuel Cell & No & No \\
\hline Micro Turbine & Yes & Yes \\
\hline Hybrid FC/MT & No & Yes \\
\hline Wind Turbine & No & Yes \\
\hline
\end{tabular}

6.2. Regarding the efficiency

\begin{tabular}{ll}
\hline \multicolumn{1}{c}{ UNIT } & \multicolumn{1}{c}{ Efficiency } \\
\hline Fuel Cell & High \\
\hline Micro Turbine & Medium \\
\hline Hybrid FC/MT & Very high \\
\hline Wind Turbine & Low \\
\hline
\end{tabular}

\subsection{Regarding the disturbance variables}

\begin{tabular}{ll}
\hline \multicolumn{1}{c}{ Unit } & \multicolumn{1}{c}{ Disturbance variables } \\
\hline Fuel Cell & Load variation \\
\hline Micro Turbine & Load variation \\
\hline Hybrid FCiMT & Load variation \\
\hline Wind Turbine & Load variation and wind speed \\
\hline
\end{tabular}

\subsection{Regarding the control variables}

\begin{tabular}{ll}
\hline \multicolumn{1}{c}{ Unit } & \multicolumn{1}{c}{ Control variables } \\
\hline Fuel Cell & Input fuel rate and the modulation index \\
\hline Micro Turbine & $\begin{array}{l}\text { Valve position and angles of the } \\
\text { Cycloconverter }\end{array}$ \\
\hline Hybrid FC/MT & $\begin{array}{l}\text { Input fuel rate, modulation index, valve } \\
\text { position and angles of the cycloconverter }\end{array}$ \\
\hline Wind Turbine & Blade pitch angle, exciter input \\
\hline
\end{tabular}

\subsection{Regarding the dynamic performance}

The presented results ensure the possibility of obtaining regulated dynamic performance when suitable controllers are developed. Regarding the dynamic operation, the MT shows the smailest overshoots either when operating alone or in the hybrid configuration and the FC shows the largest overshoots. This can be observed from the curves of the voltages and angular speeds. On the other hand, the FC can provide fast response after load variations if the input fuel rate is maintained constant. The absence of the combustions and mechanics in the FC unit results in this fast performance. However, the variation of the input fuel rate either to change the setting point or as a result of the load variation causes a slower dynamic response. This is attributed to the action of the reformer, which has a relatively large time constant.

The hybrid configuration can provide more flexibility due to the power generation from tow sources. However, the dependence of the MT on the output from the FC causes slow response of the MT with the variations of the input fuel rate. The generated power from the wind turbine has lower quality due to the continuous variations of the wind speed. Hence, complicated controllers are required.

\section{REFERENCES}

[1] V. H. M. Quezada, J. R. Abbad, and T. G. San Román, "Assessment of Energy Distribution Losses for Increasing Penetration of Distributed Generation", Power Systems, IEEE Trans. on, Vol. 21, Issue 2, Msy. 2006, pp. 533-540.

[2] W. Limpananwadi and W. Tayati, "Impacts of Multiple Distributed Generations on a Weak 
Distribution Network-ACaseStudy", International Journal of Emerging Electric Power Systems, Vol. 7 [2006], No. 2, Article 6, pp. 1-23, http://www,bepress.com/ijeeps/vol7/iss2/art6.

[3] P. A. Daly and J. Morrison, "Understanding the potential benefits of distributed generation on power delivery systems" Rural Blectric Power Conference, 29 April-1 May 2001, pp. A2-1-A213, Little Rock, Arkansas, USA.

[4] L. F. Ochoa, A. P. Feltrin, and G. P. Harrison, "Evaluating Distributed Generation Impacts With a Multi-objective Index", Power Delivery, IEEE Trans. on, Vol. 21, Issue 3, July 2006, pp. 14521458.

[5] Ahmed M. Azmy and I. Erlich, "Dynamic simulation of fuel cells and micro-turbines integrated with a multi-machine network" Power Tech Conference Proceedings, 2003 IEEE Bologna, Italy, Vol. 2, June 23-26, 2003, pp. 550555.

[6] Ahmed M. Azmy and I. Erlich, "Identification of dynamic equivalents for distribution power networks using recurrent ANNs" IEEE 2004 Power Systems Conference and Exposition, October 10-13, 2004, New York City.

[7] Ana 1. Estanqueiro, "A Dynamic Wind Generation Model for Power Systems Studies", Power Systems, IEEE Trans. on, Vol. 22, Issue 3, Aug. 2007, pp. 920-928.

[8] Amer Al-Hinai and Ali Feliachi, "Dynamic modelling of a micro turbine used as a distributed generator" System Theory 2002, Proceedings of the 34th Southeastern Symposium on, Huntsville, Alabama, 18-19 March 2002, pp. 209-213.

[9] A. Emadi, K. Rajashekara, S. S. Williamson, and S. M. Lukic, "Topological Overview of Hybrid Electric and Fuel Cell Vehicular Power System Architectures and Configurations", Vehicular
Technology, IEEE Transactions on, Vol. 54, Issue 3, May 2005, pp. 763-770.

[10] I. Erlich, J. Kretschmann, J. Fortmann, S. M. Engelhardt and $\mathrm{H}$. Wrede, "Modeling of Wind Turbines Based on Doubly-Fed Induction Generators for Power System Stability Studies", Power Systems, IEEE Trans. on, Vol. 22, Issue 3, Aug. 2007, pp. $909-919$.

[11] H. H. Hwang and L. J. Gilbert, "Synchronization of wind turbine generators against an infinite bus under gusting wind conditions", Power Apparatus and Systems, IEEE Transactions on, Vol. PAS-97, no.2, March/April 1978.

[12] In-Su Bae, Jin-O Kim, Jae-Chul Kim and C. Singh, "Optimal operating strategy for distributed generation considering hourly reliability worth" Power Systems, IEEE Transactions on, Vol. 19, No. 1, February 2004.

[13] I. Varga, K M. Hangos and F. Szigeti, "Controllability and observability of heat exchanger networks in the time-varying parameter case" Control Engineering Practice, Vol. 3, Issue. 10, October, 1995, pp. 1409-1419.

[14] F. V. Edwards, G. J. W. Dudgeon, J. R. McDonald and W. E. Leithead, "Dynamics of distribution networks with distributed generation" Power Engineering Society Summer Meeting, Seattle, Washington, USA, $2000 \mathrm{IEEE}$, Vol. 2, 16-20 July 2000 , pp. 1032-1037.

[15] Shinji Kimijima and Nobuhuide Kasagi, "Performance evaluation of gas turbine-fuel cell hybrid micro generation system" Proceedings of ASME TURBO EXPO 2002, June 3-6, 2002, Amsterdam, the Netherlands.

[16] F. Jurado and J. Saenz, "Adaptive control of a fuel cell-microturbine hybrid power plant" Power Engineering Society Summer Meeting, 2002 IEEE, Chicago USA, Vol. 1, pp. 76-81. 